\title{
A variable growth rate modification of von Bertalanffy's equation for aquaculture
}

\author{
R. R. SPRINGBORN \& A. L. JENSEN School of Natural Resources, University of \\ Michigan, Ann Arbor, Michigan, USA \\ W. Y. B. CHANG Division of International Programs, National Science Foundation, \\ Washington, DC, and Center for Great Lakes and Aquatic Sciences, the University of \\ Michigan, Ann Arbor, Michigan, USA
}

\begin{abstract}
In aquaculture experiments of only a few months' duration, fish can approach their asymptotic size and growth rates may change greatly. One objective of aquaculture is to obtain a maximum economic return, and a growth model is needed to relate rate of growth to food consumption and other costs to find the optimum duration of growth cycles. Von Bertalanffy's equation is an asymptotic growth model which can be used for this purpose. A variable growth rate model was developed to describe fish growth oscillations observed in aquaculture experiments. This growth model provides improved estimates of von Bertalanffy's equation in aquaculture and can be used for an efficient evaluation of fish production during production cycles.
\end{abstract}

\section{Introduction}

Seasonal variability is a characteristic of the growth of many fishes in nature. This is universal outside tropical regions, and is by no means rare within them, where it is usually related to seasonal rainfall. There are extremes such as the Alaska blackfish, Dallia pectoralis Bean, that hibernate like frogs at the bottom of tundra ponds, or the African lungfish, Protopterus annectens (Owen), that retreat into a cocoon far down in the mud during the dry season. Under less severe conditions there have been a number of investigations showing that growth tends to follow the cycle of the seasons, usually faster in summer and slower in winter (Ricker 1979). An example is Alexander \& Shetter's (1961) study of brook trout, Salvelinus fontinalis (Mitchill), and rainbow trout, Oncorhynchus mykiss Walbaum, in a Michigan lake. Growth was very slow from late December to early April, but did not stop entirely. Bluegill, Lepomis macrochirus Rafinesque, ceased to grow during cool weather in several Indiana lakes (Gerking 1966), while in ponds common carp, Cyprinus carpio L., sometimes lost weight in winter. Similarly, a species that must endure summer temperatures considerably greater than its preferred temperature may feed little and stop growing at that season; indeed, growth may slow down even if the fish continue to feed at their maximum rate for the prevailing temperature (Ricker 1979). Variable rates of growth observed in fishery data collected over several years are often related to seasonal patterns of temperature and rainfall and are therefore referred to as seasonal growth oscillations.

Correspondence: Dr Robert Richard Springborn, 26651 Myrtle Lane NE Apt. C201, Kingston, Washington 98346, USA. 
Von Bertalanffy's equation is a simple growth model in which fish growth to an asymptotic size is described in terms of biologically meaningful parameters of asymptotic size and a growth coefficient. This model has been widely applied to describe growth of fish in fishery applications (e.g. Beverton \& Holt 1957; Ricker 1975, 1979). In fisheries, several versions of von Bertalanffy's equation have been published to describe seasonal growth oscillations (Ursin 1963; Pitcher \& Macdonald 1973; Lockwood 1974; Daget \& Ecoutin 1976; Cloern \& Nichols 1978; Pauly \& Gaschutz 1979).

In aquaculture experiments of even a few months' duration fish may reach their asymptotic size (Springborn 1991) and growth rates may change greatly. In aquaculture we refer to variable rates of growth rather than seasonal rates of growth because the short duration of the experiment makes relating these changes to seasonal patterns difficult. One objective of aquaculture is to obtain a maximum economic return, and a growth model is needed to relate rate of fish growth to food consumption and other costs to find the optimum duration of growth cycles. Springborn (1991) reported that the initial value solution, a modification of von Bertalanffy's equation, gave improved growth parameter estimates for aquaculture. However, this growth model could not explain variable rates of fish growth. To our knowledge, a variable growth rate modification of von Bertalanffy's equation has not been reported for aquaculture. The purpose of this study was to evaluate a variable growth rate modification of von Bertalanffy's equation for predicting fish growth in aquaculture experiments.

\section{Model development}

For fisheries applications, the seasonal growth model reported by Pauly \& Gaschutz (1979) was derived from von Bertalanffy's equation. Von Bertalanffy's equation for growth in length is (Beverton \& Holt 1957; Ricker 1975)

$L_{t}=L_{\text {inf }}\left\{1-\exp \left[-\mathrm{K}\left(t-t_{0}\right)\right]\right\}$

where $L_{t}$ is length and time $t, L_{\text {inf }}$ is asymptotic length, $\mathrm{K}$ is a growth coefficient and $t_{0}$ is theoretical fish age at zero size. Von Bertalanffy's equation for growth in weight can be derived from the power relation between fish weight and length

$W_{t}=\mathrm{a} L_{t}^{\mathrm{b}}$

Substituting von Bertalanffy's equation for growth in length (equation 1) into equation (2) gives (Beverton \& Holt 1957; Ricker 1975)

$W_{t}=W_{\text {inf }}\left\{1-\exp \left[-\mathrm{K}\left(t-t_{0}\right)\right]\right\}^{\mathrm{b}}$

where $W_{t}$ is weight at time $t$ and $W_{\text {inf }}$ is asymptotic weight.

The Pauly \& Gaschutz (1979) seasonal growth model for growth in length is

$$
\begin{aligned}
L_{t}=L_{\text {inf }}\{1-\exp [ & -\mathrm{K}\left(\left(t-t_{0}\right)\right. \\
& \left.\left.\left.-C(2 \pi)^{-1} \sin 2 \pi\left(t-t_{\mathrm{s}}\right)\right)\right]\right\} .
\end{aligned}
$$

For growth in weight this model becomes

$$
\begin{aligned}
W_{t}=W_{\text {inf }}\{1-\exp [ & -\mathrm{K}\left(\left(t-t_{0}\right)\right. \\
& \left.\left.\left.-C(2 \pi)^{-1} \sin 2 \pi\left(t-t_{\mathrm{s}}\right)\right)\right]\right\}^{\mathrm{b}} .
\end{aligned}
$$


Equations (4) and (5) include an equation for simple harmonic motion which describes the growth oscillations or seasonal growth. The parameter $C$ expresses amplitude of the growth oscillations, and the parameter $t_{\mathrm{s}}$ is initial phase and expresses time between hatching $(t=0)$ and the onset of the first growth oscillation. The equation for simple harmonic motion has the form (Kaplan 1981)

$$
\mathrm{y}(t)=A \sin (\omega t+\alpha)
$$

where $A$ is amplitude, $\omega$ is frequency and $\alpha$ is initial phase. For equations (4) and (5) amplitude $A$, period $\tau$ and initial phase $\alpha$ have the form

$$
\begin{aligned}
& A=C(2 \pi)^{-1} \quad \text { where } 0 \leqslant C \leqslant 1 \\
& \tau=2 \pi / \omega=2 \pi / 2 \pi=1 \text { year } \\
& \alpha=2 \pi t_{s} .
\end{aligned}
$$

It is difficult to estimate the growth parameters of equations (1) and (3-5) in aquaculture (Springborn 1991). The initial value solution of von Bertalanffy's growth equation provides improved growth parameter estimates for aquaculture. The initial value solution for length (Beverton \& Holt 1957; Springborn 1991) is

$L_{t}=L_{\text {inf }}[1-\exp (-\mathrm{K} t)]+L_{0} \exp (-\mathrm{K} t)$

where $L_{0}$ is initial length. The initial value solution for growth in weight (Springborn 1991) is

$W_{t}=\left\{W_{\text {inf }}^{1 / \mathrm{b}}\left[1-\exp (-\mathrm{K} t)+W_{0}^{1 / \mathrm{b}} \exp (-\mathrm{K} t)\right\}^{\mathrm{b}}\right.$

where $W_{0}$ is initial weight.

The variable growth rate modification of von Bertalanffy's equation (variable growth rate model) was based on the seasonal growth model [equations (4) and (5)] and the initial value solution [equations (6) and (7)]. The variable growth rate model for growth in length is

$L_{f}=L_{\mathrm{inf}}[1-\exp (G(t))]+L_{0} \exp (-\mathrm{K} t)$

where $G(t)=-\mathrm{K} t\left[1+C(\pi)^{-1} \sin \eta \pi\left(t-t_{\mathrm{s}}\right)\right]$. The term $G(t)$ includes the equation for simple harmonic motion which describes the growth oscillations or variable rates of growth. The variable growth rate model for weight is

$W_{t}=\left\{W_{\mathrm{inf}}^{1 / \mathrm{b}}[1-\exp (G(t))]+W_{0}^{1 / \mathrm{b}} \exp (-\mathrm{K} t)\right\}^{\mathrm{b}}$.

The amplitude $A$, period $\tau$ and initial phase $\alpha$ of the variable growth rate model have the form

$$
\begin{aligned}
& A=C(\pi)^{-1} \quad \text { where } 0 \leqslant C \leqslant 1 \\
& \tau=2 \pi / \omega=2 \pi / \eta \pi=2 \eta^{-1} \text { years } \\
& \alpha=\eta \pi t_{s} .
\end{aligned}
$$

If no growth oscillations are present in the data, then $C=0$ and equations ( 8 ) and ( 9 ) reduce to the initial value solution of equations (6) and (7), respectively. In the seasonal growth model the period of seasonal growth oscillation was fixed at 1 year but in the variable growth rate model the period of variable growth oscillation is estimated from the data.

Parameter estimates for equations (2), (6) and (8) were obtained using the multivariate secant or false position method on SAS (Statistical Analysis System 1985). Parameter estimates for growth in length [equations (6) and (8)] and the power equation [equation (2)] 
were used to derive parameter estimates for growth in weight [equations (7) and (9), respectively] by simple substitution.

\section{Research facilities and data collection}

Data for evaluation of the variable growth rate model were from an experiment consisting of 12 pond replicates which began on 1 August 1984 and ended on 4 January 1985. Each pond (0.022 ha) was stocked with $23.0 \mathrm{~g}, 10.7 \mathrm{~cm}$, all-male (hand-sexed) Nile tilapia, Oreochromis niloticus (L.), at a rate of $10000 /$ ha. Each pond was treated with triple superphosphate $\left(\mathrm{P}_{2} \mathrm{O}_{5}\right.$; TSP) at a rate of $2 \mathrm{~kg} /\left(\mathrm{ha}^{*}\right.$ week). At monthly intervals 20 fish were sampled with replacement from each pond to obtain average length and weight measurements. After 156 days, mean fish size at harvest was $70.5 \mathrm{~g}$ and $15.9 \mathrm{~cm}$. Detailed methods can be found in CRSP (1983).

\section{Results and discussion}

One objective of aquaculture is to obtain a maximum economic return, and a growth model is needed to relate rate of growth to food consumption and other costs to find the optimum duration of growth cycles. If fish production cost per day is constant, the economic return at harvest is constantly changing because growth in weight is constantly changing. As rate of growth in weight approaches the inflection point, the economic return of fish yield at harvest increases. The economic return is a maximum at the inflection point, and then it decreases as the fish continue to grow (Springborn 1991). Von Bertalanffy's equation can be used to relate rate of growth to food consumption and other costs to find the optimum duration of growth cycles.

Springborn (1991) developed the initial value solution of von Bertalanffy's equation which uses the size of fish stocked as a model starting point instead of a theoretical age of the fish at zero size. The initial value solution does provide improved growth parameter estimates in aquaculture, but a limitation of this growth model is that it cannot describe variable growth rates. The variable growth rate model explains growth oscillations better than the initial value solution. This conclusion is based on the results of fit to observed growth in length and weight (Fig. 1) and comparison of mean square errors from the nonlinear fitting method using both growth models (Table 1). The variable growth rate model gave the same fit to observed growth in terms of sums of squares error (SSE) as the polynomial regression function,

$L_{t}=\mathrm{b}_{0} t+\mathrm{b}_{1} t^{2}+\mathrm{b}_{2} t^{3}+\mathrm{b}_{3} t^{4}+\mathrm{b}_{5} t^{5}$

where $t$ is time and $b_{0}, b_{1}, b_{2}, b_{3}, b_{4}$ are regression parameters to be estimated. Sums of squares error from fitting this model was 11.50 (Table 1) which confirms that the variable growth rate model provided the best possible fit to observed growth. Parameter estimates for $O$. niloticus growth using the variable growth rate model are in agreement with those reported by Pauly, Moreau \& Prein (1988) for O. niloticus cultured in ponds. Growth parameter estimates of the variable growth rate model are easily obtained because the growth model uses size of fish stocked as a model starting point and does not require an estimate of fish age at stocking, and several statistical software packages include nonlinear fitting procedures which do not require the additional step of estimating the derivatives. 

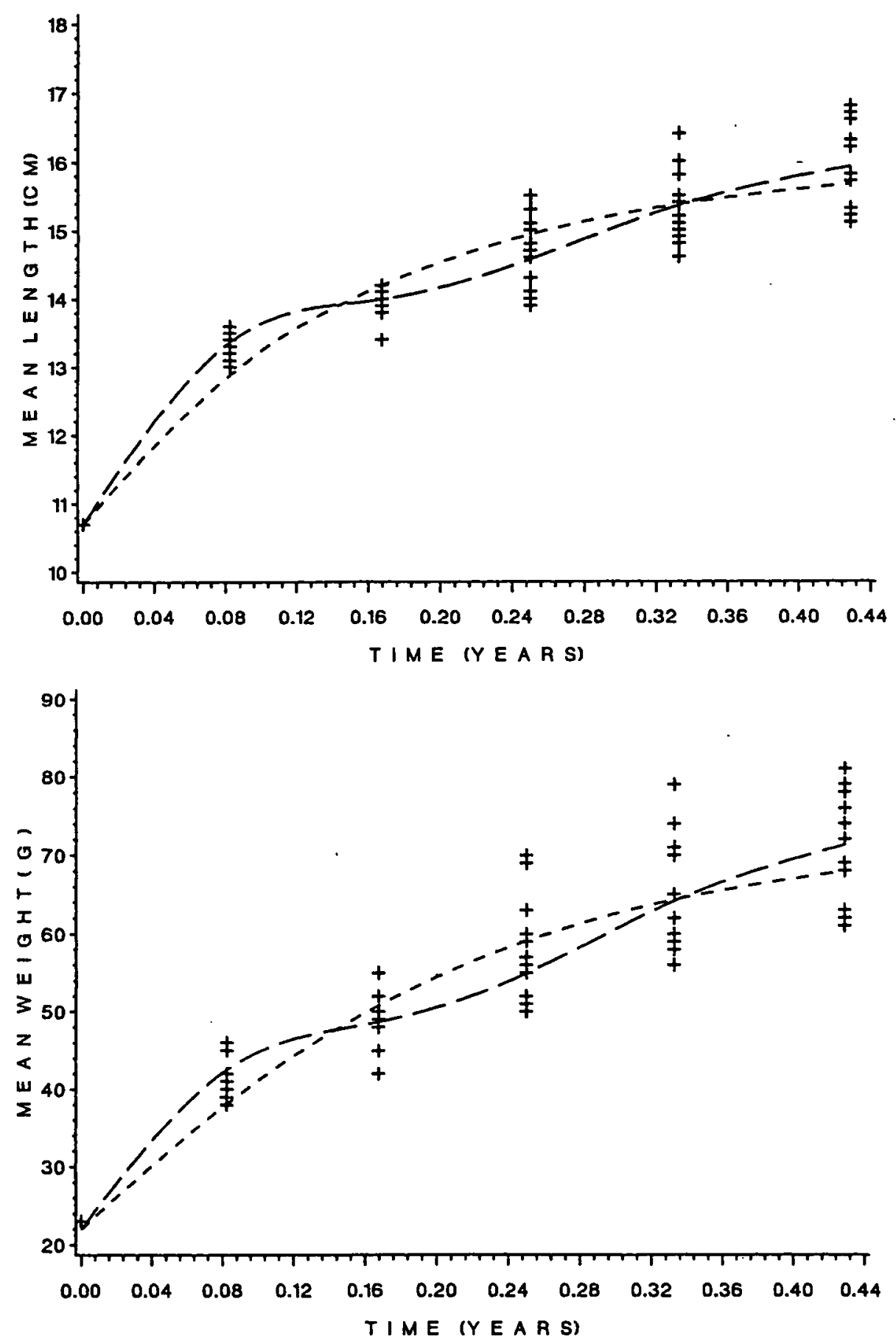

Figure 1. Predicted growth in length and weight for the variable growth rate model (long dashes) and the initial value solution (short dashes). 
Table 1. Parameter estimates for growth in length using the variable growth rate model (equation 8 ) and the initial value solution (equation 6 )*

\begin{tabular}{llllllll}
\hline Eqn & SSE $^{\dagger}$ & MSE & \multicolumn{1}{c}{$L_{\text {inf }}$} & K & $C$ & $t_{3}$ & $\eta$ \\
\hline 6 & 17.37 & 0.248 & 16.0 & 6.44 & & & \\
8 & 11.62 & 0.171 & 16.0 & 8.72 & 0.5441 & 0.4102 & 3.00 \\
Polynomial regression function, $S S E=11.50$ & & & & & &
\end{tabular}

* Power equation parameter estimates were $a=0.0195, b=2.966$.

+ Sums of squares error.

Mean square error.

Because von Bertalanffy's equation is an asymptotic growth model, a limitation of the application of the variable growth rate model is that observed growth must be asymptotic. Growth in weight as described by von Bertalanffy's equation initially increases at an increasing rate to a maximum at the inflection point of the weight curve. After this inflection point, growth in weight increases at a decreasing rate to an asymptotic size. If observed growth is not asymptotic, a simpler growth model such as a relative growth rate or instantaneous growth rate would provide a more accurate prediction of growth. However, in many aquaculture experiments, especially those using $O$. niloticus as a culture species, growth may reach an asymptotic size and the variable growth rate model would provide the most accurate prediction of fish growth.

Von Bertalanffy's growth equation was derived from bioenergetic principles of growth (Ursin 1967). Therefore the growth parameter estimates of the variable growth rate model can be interpreted in terms of fish growth. The parameters of the variable growth rate model are biologically meaningful and can be used to describe fish growth in terms of an asymptotic size $\left(L_{\text {inf }}, W_{\text {inf }}\right)$, a growth coefficient $(\mathrm{K})$, amplitude of the growth oscillation $(C)$ and the time of slowest growth $\left(t_{\mathrm{s}}\right)$. The variable growth rate model is an improvement over common statistical methods such as the polynomial regression function because the latter was a numerical method without the support of bioenergetic principles of fish growth. The parameter estimates from a numerical method such as the regression function lack the biological basis for interpreting fish growth. Cloern \& Nichols (1978) reported a modified version of von Bertalanffy's equation with a seasonally varying coefficient. Their model fit the growth data well but contained parameters that the authors failed to interpret biologically in terms of growth.

The least-squares estimate of $C$ in the variable growth rate model measures quantitatively the amplitude of growth oscillation or degree of oscillating growth. The choice of amplitude $A$ equal to $C / \pi$ provides an estimate of $C$ ranging from 0 to 1.0 instead of using an estimate of $A$ directly which would range from 0 to $\pi^{-1}$. If growth oscillations are absent, then $C=0$ and the variable growth rate model reduces to the initial value solution. The variable growth rate model encompasses all growth conditions as a comprehensive growth model for aquaculture, where the initial value solution represents a special case when no growth oscillation occurs.

The least-squares estimate of $t_{\mathrm{s}}$ in the variable growth rate model (where $t_{\mathrm{s}}=0$ at hatching) measures the time of slowest growth. If growth measurements were recorded every week over an entire year, the estimate of $t_{\mathrm{s}}$ should express the time when fish growth is minimal. In this study the estimate of $t_{s}$ was 0.4102 or about 150 days, which indicates that the time of slowest growth occurred at harvest. As fish growth approaches its asymptote, rate of 

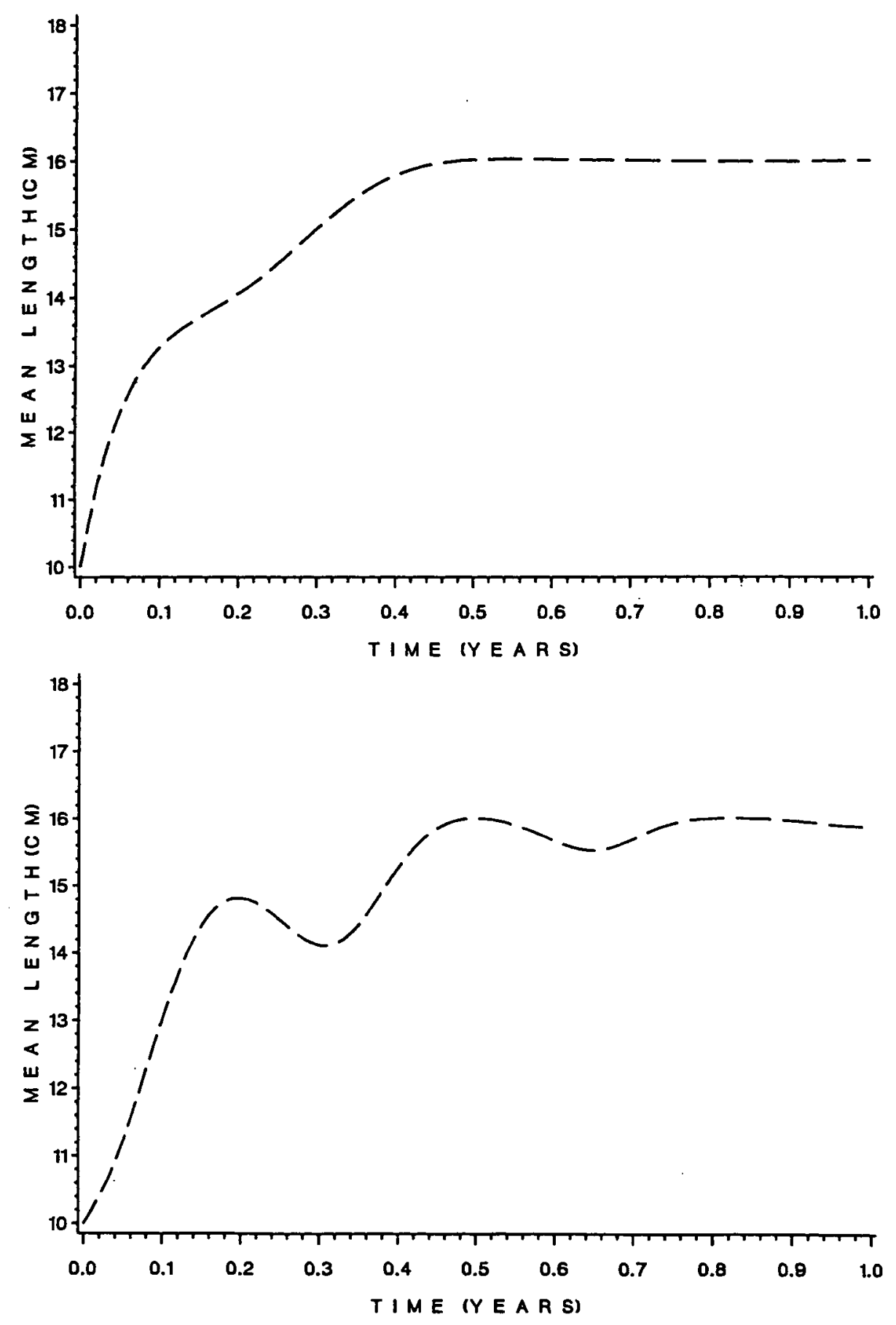

Figure 2. Predicted growth in length for the variable growth rate model, using growth parameter estimates in Table 1, illustrating $\tau=0.667$ and $K=8.72$ (top panel), and parameter estimates in Table 1 with changes to $K$ and $\eta$, illustrating $\tau=0.333$ and $K=4.36$ (bottom panel). 
growth also decreases to a minimum. Therefore as the duration of the experiment increases we would expect the estimate of $t_{s}$ to approach the time in which fish size reaches its asymptote. In this study fish size did reach its asymptote at harvest. At harvest mean length was $15.9 \mathrm{~cm}$ and mean weight was $70.5 \mathrm{~g}$ compared with an asymptotic length and asymptotic weight of $16.0 \mathrm{~cm}$ and $72.7 \mathrm{~g}$, respectively. Therefore the above estimate of $t_{\mathrm{s}}$ is realistic.

For the variable growth rate model, the estimated period of growth oscillation $\tau$ was found to be $\mathbf{0 . 6 6 7}$. Figure 2 (top panel) illustrates predicted growth in length for a period of 1 year using the parameter estimates of the variable growth rate model (Table $1, K=8 \cdot 72, \eta=3 \cdot 0, \tau$ $=0.667$ ). Figure 2 (bottom panel) illustrates the effect of increasing $\eta$ from 3.0 to 6.0 which decreases the period of growth oscillation $\tau$ from 0.667 to 0.333 , and decreasing the instantaneous rate of growth $\mathrm{K}$ from 8.72 to 4.36 . It is difficult to detect a repeating period of growth oscillation in the top plate because of the high instantaneous rate of increase in growth $\mathrm{K}$ to an asymptotic size, but if we decrease $\mathrm{K}$ from 8.72 to 4.36 and decrease the period of growth oscillation from 0.667 to 0.333 it becomes relatively easy to detect the repeating period of growth oscillation. The seasonal growth model of Pauly \& Gaschutz (1979) assumes that the period of growth oscillation is 1 year, which is reasonable because fishery managers are interested in relating growth oscillations to yearly cycles of temperature and rainfall. But in aquaculture, where experiments may last only a few months, it is difficult to relate growth to yearly cycles of temperature and rainfall. The variable growth rate model reported here is needed for aquaculture because it provides an approach to estimate this period of growth oscillation directly from the data using the parameter $\eta$ described above.

\section{Acknowledgments}

The authors thank R. Stephen Schneider for his comments and suggestions. This study was funded by a grant (No. DAN-4023-G-SS-2074-00) from the Pond Dynamics/Aquacuiture Collaborative Research Support Program (CRSP), Agency for International Development and by the matching funds for the grant from the Office of Vice President for Research, the University of Michigan to W.Y.B. Chang. Contribution no. 542 of the Center for Great Lakes and Aquatic Sciences, the University of Michigan.

\section{References}

Alexander G.R. \& Shetter D.S. (1961) Seasonal mortality and growth of hatchery-reared brook and rainbow trout in East Fish Lake, Montmorency County, Michigan, 1958-1959. Papers of the Michigan Academy of Science, Arts and Letters 46, 317-328.

Beverton R.J.H. \& Holt S.L. (1957, Facsimile reprint 1993) On the Dynamics of Exploited Fish Populations. Fishery Investigations, Ministry of Agriculture, Fisheries and Food (Great Britain), Series II, Salmon and Freshwater Fisheries, Vol. 19. Chapman \& Hall, London.

Cloern J.E. \& Nichols F.H. (1978) A von Bertalanffy growth model with a seasonally varying coefficient. Journal of the Fisheries Research Board of Canada 35, 1479-1482.

CRSP (1983) Collaborative Research Support Program Work Plan: Volume 1, First Experimental Cycle July 1983. Pond Dynamics/Aquaculture CRSP, Program Management Office, Oregon State University, Marine Science Center, Newport, Oregon 97365.

Daget J. \& Ecoutin J.M. (1976) Modeles mathematiques de production applicables aux poissons tropicaux subissant un arret prolonge de croissance. Cahiers ORSTOM, serie Hydrobiologie 10, 59-69. 
Gerking S.D. (1966) Annual growth cycle, growth potential, and growth compensation in the bluegill sunfish in northern Indiana lakes. Journal of the Fisheries Research Board of Canada 23, 1923-1956.

Kaplan W. (1981) Advanced Mathematics for Engineers. Addison-Wesley Publishing Company, Reading, Massachusetts.

Lockwood S.J. (1974) The use of the von Bertalanffy equation to describe the seasonal growth of fish. Journal du Conseil International pour l'Exploration de la Mer 35, 175-179.

Pauly D. \& Gaschutz G. (1979) A simple method for fitting oscillating length growth data with a program for pocket calculators. International Council for the Exploration of the Sea. Demersal Fish Committee. C.M. 1979/G/24.

Pauly D., Moreau J. \& Prein M. (1988) A comparison of overall growth performance of tilapia in open waters and aquaculture. In: The Second International Symposium on Tilapia in Aquaculture (ed. by R.S.V. Pullin, T. Bhukaswan, K. Tonguthai \& J.L. Maclean), pp. 469-479. ICLARM Conference Proceedings 15, Manila, Philippines.

Pitcher T.J. \& Macdonald P.D.M. (1973) Two models for seasonal growth in fishes. Journal of Applied Ecology 10, $599-606$.

Ricker W.E. (1975) Computation and interpretation of biological statistics of fish populations. Bulletin of the Fisheries Research Board of Canada 191, 1-382.

Ricker W.E. (1979) Growth rates and models. In: Fish Physiology (ed. by W.S. Hoar \& D.J. Randall), Volume VIII. Academic Press, New York.

Springborn R.R. (1991) Application of von Bertalanffy's equation to Nile tilapia (Oreochromis niloticus) growth in aquaculture experiments. PhD Dissertation, University of Michigan, Ann Arbor, Michigan.

Statistical Analysis System (SAS) (1985) SAS Users Guide: Statistics. Version 5 Edition. SAS Institute Inc., Box 8000 , Cary, North Carolina.

Ursin E. (1963) On the incorporation of temperature in the von Bertalanffy growth equation. Meddelelser fra Danmarks Fiskeri-og Havundersogelser 4, 1-16.

Ursin E. (1967) A mathematical model of some aspects of fish growth, respiration, and mortality. Journal of the Fisheries Research Board of Canada 24, 2355-2453. 
This document is a scanned copy of a printed document. No warranty is given about the accuracy of the copy. Users should refer to the original published version of the material. 